\title{
Skin allergic reaction to a spinal cord stimulation (SCS): an analysis of the world literature and a case report
}

\author{
Kamila Woźniak-Dąbrowska ${ }^{1}$, Agnieszka Nowacka ${ }^{1}$, Wojciech Smuczyński ${ }^{2}$, Maciej Śniegocki ${ }^{1}$
}

${ }^{1}$ Department of Neurosurgery, Physiotherapy, Collegium Medicum in Bydgoszcz, Nicolaus Copernicus University in Torun, Poland ${ }^{2}$ Department of Physiotherapy, Collegium Medicum in Bydgoszcz, Nicolaus Copernicus University in Torun, Poland

Adv Dermatol Allergol 2020; XXXVII (1): 114-116

DOI: https://doi.org/10.5114/ada.2020.93389

One of the methods of treating chronic pain is the neuromodulatory procedure - spinal cord stimulation (SCS). The mechanism of its operation is not fully understood. The first clinical applications were based on the gate control theory of pain proposed by Melzack and Wall in 1965, which is about the central inhibition of pain by non-painful stimuli [1]. Based on this theory, in March 1967, an American neurosurgeon Norman Shealy, by Th1Th3 laminectomy, implanted a device for stimulating the posterior columnar spinal column in a 70-year-old patient with a pulmonary pain syndrome. Another mechanism explaining the action of SCS is a segmental blockade of neural transmission of pain stimuli, resulting from local changes in the spinal cord and spinal neurons, which are responsible for the conduction and modulation of pain [2].

The main indication for spinal cord stimulation is neuropathic pain, which arises as a result of nerve compression, trauma, ischemic, metabolic (e.g. diabetic neuropathy) and postinfectious (e.g. postherpetic neuralgia) pain. Spinal cord stimulation is used in CRPS type I and CRPS type II syndromes, after neurosurgical operations in the failed back surgery syndrome and post-laminectomy syndrome, in angina pectoris, multiple sclerosis, peripheral vascular disease, arachnoiditis, shoulder plexus injuries and spinal cord injuries [3].

Neurostimulation is a modern method of treatment using electrical impulses. An electric pulse acting on the nerve cell causes a change in the voltage on its surface, so-called depolarization. Stimulation blocks the pain signal so that it does not reach the brain or is not read by the brain as a sensation of pain. The system for stimulating the core consists of three elements: a pulse generator, an electrode placed in the spinal canal and a connector. Electrical stimulation can stimulate or inhibit the neuronal activity, thanks to which it is possible to obtain a change of pain to cover paraesthesia [4]. Neuromodu- lation techniques allow to reduce pain sensations and are relatively safe for patients. However, in a small percentage of clinical cases, there is a local allergic reaction of the skin after implantation of a spinal cord analgesic stimulator (SCS). The authors carried out an analysis of the clinical case of a surgical patient undergoing surgery at the Department of Neurosurgery, Neurotraumatology and Children's Neurosurgery, Antoni Jurasz University Hospital No. 1 in Bydgoszcz, where it was necessary to remove the anal spinal cord stimulator due to a local skin allergic reaction; the analysis also included articles from the world literature available on the subject.

A 47-year-old patient was admitted to the Department of Neurosurgery in 2016 for the purpose of implanting a SCS. The interview demonstrated the state after multiple surgical treatment of the L-S spine (decompression of the spinal canal in the L4-L5 segment, stabilization by the epiphyseal TPF L4-S1), FBSS (failed back surgery syndrome). From 2015, the patient's pain prevented daily activities. The patient was qualified for surgical treatment: namely implantation of the SCS spinal cord stimulator. The patient was placed on her stomach. Disinfection and occupancy of the operating field were performed. After localization of the operated level, the vertebral arches and flavoplegia were made at the Th10 level. The electrode was inserted into the spinal canal, pointing it upwards. Next, a pocket was created for the battery in the area of the right hip pad. The wires from the electrodes were placed subcutaneously from the thoracic region to the battery area. The system was checked and the batteries were connected to the electrode leads. The battery was placed in the prepared pocket near the hip plate. Tubing in the thoracic region was taped to create a "supply" of wires in the subcutaneous tissue of the surgical area. On the second day after surgery, the patient was discharged home in a general and locally good condition. After about

Address for correspondence: Agnieszka Nowacka, Department of Neurosurgery, Nicolaus Copernicus University, Collegium Medicum, 9 M. Skłodowskiej-Curie St, 85-094 Bydgoszcz, Poland, e-mail: dr.agnieszka.nowacka@gmail.com Received: 21.07.2018, accepted: 29.07.2018. 
a month the patient was admitted again to the Clinic. The patient reported an improvement in pain after pacemaker implantation, but in the projection of the implanted battery there appeared redness, which in the patient's opinion causes severe pain and pruritus. The patient was consulted dermatologically and skin tests were performed (European standard of 30 basic contact allergens). A metal-induced contact dermatitis was diagnosed allergically. The patient was treated with topical (steroid ointment, emollients) and general drugs (anti-histamine drugs). The patient was offered to have the SCS stimulator removed. At first, the patient did not consent to neurosurgical intervention, however, due to persistent complaints, the patient returned to the Clinic again after a month to have the surgical operation to remove the SCS analgesic stimulator. The procedure was uncomplicated. On the first day after the removal of the stimulator, a reduction in local skin reaction in the area of the iliac plate was observed. The patient also reported a marked reduction in pruritus in the area. She was discharged home in a general and good local condition.

Contact allergy is a kind of hypersensitivity of the organism to low molecular weight chemical substances or proteins induced by direct contact of these substances with the skin. Contact allergy affects approximately 20-30\% of all adults [5]. Contact sensitization detected on the basis of positive skin test results is the cause of allergic contact dermatitis (ACD). Skin lesions are characterized by exudative symptoms such as erythema, oedema, vesicles, erosions, outbreaks of filtering or symptoms of laceration of the skin: thickening of the epidermis, cracks, exfoliation of the epidermis [6]. Changes in disease are usually accompanied by severe pruritus. Sensitization may arise simultaneously or after a certain period of time. Metals are among the most common allergens. Nickel is the most common contact allergen worldwide [7].

In the available world literature, there are not many reports of clinical cases of cutaneous allergic reaction to the SCS stimulator.

In the clinical case described by us, the patient's skin test readings after 48 and $72 \mathrm{~h}$ were as follows: nickel sulphate $(++)$, palladium chloride $(++)$, and other allergens (-). Both metals are components of the pacemaker battery.

Chaudhry et al. describe a clinical case of a 61-yearold man, who 7 days after the surgical procedure of implanting the SCS stimulator had skin rash and increased pruritus in the area of the implanted battery. In the case of the patient, as in the case described by us, local (steroid ointment) and general (histamine) medications were initially used. On the $43^{\text {rd }}$ day after surgery, due to the patient's continued pruritus and rash, the pacemaker was removed [8]. In the described clinical case, the patient's skin test readings were as follows: nickel sulphate (++), palladium chloride $(++)$, and other allergens (-).
In 2012, Zhou et al. described a clinical case of a man who also had a skin rash and increased pruritus around the implanted battery [9]. The applied conservative treatment did not bring any significant improvement to the patient and the stimulator was removed. In the described clinical case, the patient's skin test readings were as follows: nickel sulphate $(++)$, palladium chloride $(++)$, and other allergens (-).

Allergy to nickel is a serious health problem for modern societies. Allergy to this metal is found in $13 \%$ of adults and $8 \%$ of children [10]. The most common symptom of allergy to nickel is allergic contact dermatitis. Clearly, allergic conjunctivitis, rhinitis, bronchial asthma and urticaria are more rare. In 1982, nickel allergy was noted in about $16 \%$ of respondents, and in the 1990s in 22\% [11]. In 1990-1991, the percentage of people allergic to nickel was $11.1 \%$ in women and $2.2 \%$ in men. Hypersensitivity usually arises as a result of contact with jewellery, metal parts of machines, tools, coins, bracelets from watches. The chloride content in the sweat plays a major role in the formation of nickel dermatitis - the higher the content, the more likely it is to develop allergies. The development of contact allergy to nickel is played by/is due to both Th2/Tc2 (IL-4, IL-5, IL-13) and Th1/c1 (IFN- $\gamma$ ) lymphocytes.

Currently, three mechanisms are known [12] by means of which nickel initiates an immune response:

a) nickel binding to proteins causes a change in their spatial conformation, which causes their recognition by the immune system as foreign structures - antigen presenting cells capture, metabolize and present fragments of these proteins on class II ( $\mathrm{MCH}$ II) tissue conformal complexes in a form capable of being recognized by the CD4+ T cell receptor.

b) nickel binds to intracellular proteins that are degraded in lysosomes, after which the degradation products are presented on class I tissue (IOC) complexes in a form that permits their recognition by the CD8+ T cell receptor.

c) nickel may form bonds between the MHC complex and the lymphocyte receptor in the way independent of metabolism in a process similar to the effect of superantigens - after contact with immunogenic nickel complexes with proteins, they migrate to the dermis and further through the lymphatic vessels to the local lymph nodes.

Until now, the importance of Th1 lymphocytes and their main INF- $\gamma$ cytokine in the pathogenesis of contact allergy to nickel has been underlined. Currently, the contribution of Th2/Tc2 cytokines to the pathogenesis of nickel hypersensitivity is also underlined. Śpiewak et al. in their study showed the best correlation of clinical diagnosis and patch test with the level of IL-13, while the level of IL-2 best correlated with the lymphocyte proliferation test [13]. The authors point to a significant role of IL-5 and IL-13 in allergy to nickel, and their level increases 
especially after administration of IL-7 and IL-4 cytokines - conducive to the survival and development of Th2 and Tc2 lymphocytes.

Interestingly, none of the three patients described had previous allergy to this metal or dysfunction suggesting a predisposition to skin reactions.

In conclusion, nickel is the most common contact allergen worldwide. Contact allergy affects about 20-30\% of all adults. Contact allergy may occur after the implantation of the SCS stimulator.

\section{Conflict of interest}

The authors declare no conflict of interest.

\section{References}

1. Rigoard P, Delmotte A, Moles A, et al. Successful treatment of pudendal neuralgia with tricolumn spinal cord stimulation. Neurosurgery 2012; 71: 757-63.

2. Lindenroth B, Meyerson BA. Spinal cord stimulation: I. Mechanism of action. In: Surgical Management of Pain. Burchiel KJ (ed.). Thieme, New York 2002; 505-26.

3. Kumar K, Taylor RS, Jacques I, et al. Spinal cord stimulation versus conventional medical management for neuropathic pain: a multicentre randomized controlled trial in patients with failed back surgery syndrome. Pain 2007; 132: 179-88.

4. Grider JS, Manchikanti L, Carayannopoulos A, et al. Effectiveness of spinal cord stimulation in chronic spinal pain: a systematic review. Pain Physician 2016; 19: E33-54.

5. Kieć-Swierczyńska M, Kręcisz B. Dynamika uczulenia kontaktowego u 10 podstawowych alergenów w ostatnim dwudziestoleciu. Przegl Dermatol 1997; 84: 121-8.

6. Kieć-Swierczyńska M. Occupational allergic contact dermatitis in Lodz 1990-1994. Occup Med 1996; 46: 205-8.

7. Akdis M, Schmid-Weber C, Jutel M, et al. Mechanism of allergen immunotherapy. Allergy Clin Immunol Int - J World Allergy Org 2004; 16: 65.

8. Chaudhry Z, Najib U, Bajwa Z, et al. Detailed analysis of allergic cutaneous reactions to spinal cord stimulator device. J Pain Res 2013; 6: 617-23.

9. Zhou L, Lee A, Schaffner R, et al. Allergic reaction to a peripheral nerve stimulator. Open Neurosurg J 2012; 5: 12-5.

10. Antoszczyk G, Obtułowicz K. Systemowe działanie niklu. Post Dermatol Alergol 2005; 22: 29-36.

11. Buczytko K. Nie tylko alergeny: nikiel. Alergia 2014; 4: 24-7.

12. Simonsen AB, Deleuran M, Mortz CG, et al. Allergic contact dermatitis in Danish children referred for patch testinga nationwide multicentre study. Contact Dermatitis 2014; 70: 104-11.

13. Śpiewak R. Alergiczne kontaktowe zapalenie skóry u dzieci. Nowa Medycyna 2001; 8: 23-6. 